\title{
NMD inhibition fails to identify tumour suppressor genes in microsatellite stable gastric cancer cell lines
}

\author{
Tineke E Buffart ${ }^{1}$, Marianne Tijssen ${ }^{1}$, Jamila El-Bchiri², Alex Duval ${ }^{2}$, Mark A \\ van de Wiel ${ }^{1,3}$, Bauke Ylstra1, Gerrit A Meijer ${ }^{1}$ and Beatriz Carvalho*1,4
}

Address: ${ }^{1}$ Dept Pathology, VU University Medical Center, Amsterdam, The Netherlands, ${ }^{2}$ INSERM U434, Hôpital Saint-Louis, Paris, France, ${ }^{3}$ Dept Mathematics, VU University Medical Center, Amsterdam, The Netherlands and 4 IPATIMUP, Department of Pathology, Medical Faculty, Hospital de S. João, Porto, Portugal

Email: Tineke E Buffart - t.buffart@vumc.nl; Marianne Tijssen - m.tijssen@vumc.nl; Jamila El-Bchiri - elbchiri@cephb.fr; Alex Duval - alex.duval@cephb.fr; Mark A van de Wiel - mark.vdwiel@vumc.nl; Bauke Ylstra - b.ylstra@vumc.nl; Gerrit A Meijer - ga.meijer@vumc.nl; Beatriz Carvalho* - b.carvalho@vumc.nl

* Corresponding author

Published: 29 June 2009

BMC Medical Genomics 2009, 2:39 doi:10.1186/1755-8794-2-39
Received: 3 October 2008

Accepted: 29 June 2009

This article is available from: http://www.biomedcentral.com/1755-8794/2/39

(C) 2009 Buffart et al; licensee BioMed Central Ltd.

This is an Open Access article distributed under the terms of the Creative Commons Attribution License (http://creativecommons.org/licenses/by/2.0), which permits unrestricted use, distribution, and reproduction in any medium, provided the original work is properly cited.

\begin{abstract}
Background: Gastric cancers frequently show chromosomal alterations which can cause activation of oncogenes, and/or inactivation of tumour suppressor genes. In gastric cancer several chromosomal regions are described to be frequently lost, but for most of the regions, no tumour suppressor genes have been identified yet. The present study aimed to identify tumour suppressor genes inactivated by nonsense mutation and deletion in gastric cancer by means of GINI (gene identification by nonsense mediated decay inhibition) and whole genome copy number analysis.
\end{abstract}

Methods: Two non-commercial gastric cancer cell lines, GP202 and IPA220, were transfected with siRNA directed against UPFI, to specifically inhibit the nonsense mediated decay (NMD) pathway, and with siRNA directed against non-specific siRNA duplexes (CVII) as a control. Microarray expression experiments were performed in triplicate on $4 \times 44 \mathrm{~K}$ Agilent arrays by hybridizing RNA from UPFI-transfected cells against non-specific CVII-transfected cells. In addition, array CGH of the two cell lines was performed on $4 \times 44 \mathrm{~K}$ agilent arrays to obtain the DNA copy number profiles. Mutation analysis of GINI candidates was performed by sequencing.

Results: UPFI expression was reduced for $>70 \%$ and $>80 \%$ in the GP202 and IPA220 gastric cancer cell lines, respectively. Integration of array $\mathrm{CGH}$ and microarray expression data provided a list of 134 and 50 candidate genes inactivated by nonsense mutation and deletion for GP202 and IPA220, respectively. We selected 12 candidate genes for mutation analysis. Of these, sequence analysis was performed on II genes. One gene, PLA2G4A, showed a silent mutation, and in two genes, CTSA and PTPRJ, missense mutations were detected. No nonsense mutations were detected in any of the II genes tested.

Conclusion: Although UPFI was substantially repressed, thus resulting in the inhibition of the NMD system, we did not find genes inactivated by nonsense mutations. Our results show that the GINI strategy leads to a high number of false positives. 


\section{Background}

As many other solid tumours, gastric cancer develops through an accumulation of genetic and epigenetic alterations. Although the knowledge of genetic and epigenetic events occurring in gastric cancer is increasing, it is still far from being complete.

Two major types of genetic instability are described in gastric cancer, chromosomal instability and microsatellite instability[1]. Chromosomal instable tumours show gross chromosomal abnormalities leading to loss and or gain of large genomic areas, while microsatellite instable tumours show an increased mutation rate at the nucleotide level and in general do not show gross chromosomal abnormalities. The majority of gastric cancers have a chromosomal instable phenotype and many studies have been published describing frequent occurrence of chromosomal aberrations in gastric cancers [2-11]. Chromosomal alterations can cause activation of oncogenes, by increasing the copy number, and/or inactivation of tumour suppressor genes, by loss of alleles. In case of tumour suppressor genes, usually both alleles must be inactivated in order to abrogate the function of a gene, which can be achieved by any combination of loss, mutation, or promoter hypermethylation. In gastric cancer several chromosomal regions have been described to be frequently lost $[6,11,12]$, but in most of these regions, no tumour suppressor genes have been identified yet.

In eukaryote cells, mRNAs molecules that contain premature termination codons (PTCs) due to nonsense mutations are detected and rapidly degraded by the nonsensemediated decay (NMD) mechanism. NMD is mediated through the assembly of protein complex coded by genes such as the ones belonging to the UPF family e.g. RENT-1/ UPF1, RENT-2/UPF2, UPF-3A, and UPF-3B[13]. RENT-1/ UPF1 has been shown to play a crucial role in the function of the NMD system. Taking advantage of the existence of this regulatory system in the cells, Noensi and Dietz described a strategy, called GINI (Gene Identification by Nonsense-mediated decay Inhibition), to identify tumour suppressor genes harbouring premature stop-codons[14]. Microarrays are used to identify potential nonsense transcripts that are increased in abundance after inhibition of the NMD system, by comparing the sample to itself after inhibition of NMD. The NMD pathway can be pharmacologically blocked by treating the cells with a translation inhibitor, such as emetine, resulting in stabilization of mutated transcripts containing a premature stop-codon. However, this drug also induces a stress response resulting in increased mRNA levels of many transcripts. To more specifically inhibit the NMD pathway, a different strategy has been described in which a siRNA directed against UPF1 is used $[15,16]$.
The combination of NMD microarray data on putative nonsense mutations with array CGH data on deleted genomic areas enables the detection of biallelic inactivation events of tumour suppressor genes, as shown previously in prostate cancer[17]. Therefore, the present study aims to identify tumour suppressor genes inactivated by nonsense mutation and deletion in gastric cancer by means of GINI and whole genome DNA copy number analysis.

\section{Methods \\ Cell lines and cell culture}

Two non-commercial gastric cancer cell lines, GP202 and GP220, established and characterized in IPATIMUP, Porto[18] were used for siRNA transfection. These particular cell lines were derived from two different patients and were not immortalized by viral infection. The cell lines were maintained in RPMI supplemented with $10 \%$ fetal calf serum, $100 \mathrm{U} / \mathrm{mL}$ penicillin, $100 \mu \mathrm{g} / \mathrm{mL}$ streptomycin and $2 \mathrm{mmol} / \mathrm{L}$ L-glutamine (Life Technologies, Breda, NL).

\section{DNA isolation and Array CGH}

Genomic DNA was isolated using TRIzol reagent (Invitrogen, Breda, NL) according to the manufacturer's protocol with some modifications http://www.vumc.com/afdelin gen/microarrays/. DNA isolated from blood obtained from eighteen healthy males was pooled and used as normal reference. DNA concentrations were measured on a Nanodrop ND-1000 spectrophotometer (Isogen, IJsselstein, NL). $500 \mathrm{ng}$ of DNA was labelled using the Enzo Genomic DNA Labelling kit as described previously (Enzo Life Sciences, Farmingdale, USA)[19]. Hybridizations were performed on slides containing four arrays, with each array containing 45220 in-situ synthesized 60-mer oligonucleotides, representing 42494 unique chromosomal locations (Agilent Technologies, Palo Alto, USA)[19].

Images of the arrays were acquired using a microarray scanner G2505B (Agilent technologies) and image analysis was performed using feature extraction software version 9.5 (Agilent Technologies,). The Agilent CGH-v4_95 protocol was applied using default settings. Oligonucleotides were mapped according to the human genome build NCBI 35 (May 2004). For both Cy3 and Cy5 channels, local background was subtracted from the median intensities. The $\log _{2}$ tumour to normal ratio was calculated for each spot and normalized against the median of the ratios of all autosomes.

\section{UPFI siRNA transfection}

Transfection of both cell lines was performed in $35 \mathrm{~mm}$ dishes with $100 \mathrm{nM}$ of siRNA duplexes directed against UPF1 (Dharmacon, Chicago, IL) or non-specific siRNA 
duplexes (CVII) (Dharmacon) using the lipofectamine 2000 reagent (Invitrogen) according to the manufacturer's instructions. Cells were collected for total RNA extraction $72 \mathrm{~h}$ after transfection. Each transfection experiment was performed in duplicate on three different days.

RNA isolation procedures and quantitative real-time PCR Total RNA was extracted from each cell line using the RNeasy kit (Qiagen, Westburg, Leusden, NL) including a DNase digestion step, according to the manufacturer's instructions. Concentrations were measured on a Nanodrop ND-1000 spectrophotometer (Isogen). Synthesis of cDNA was performed with random primers using the high capacity cDNA Archive Kit kit (Applied Biosystems). SDS 2.1 Applied Biosystems analysis software was used to determine the $\mathrm{Ct}$ number at which increase in signal is associated with exponential amplification of the PCR products, needed to quantify the expression values. Quantification of the $18 \mathrm{~S}$ ubiquitous RNA was used as the endogenous reference. The delta $\mathrm{Ct}$ was determined in each case by subtracting the average $\mathrm{Ct}$ value of the target gene from the average $\mathrm{Ct}$ value of the $18 \mathrm{~S}$ gene. The percentage of inhibition of the UPF1 gene was calculated by subtracting the mean delta ct of the UPF1 siRNA transfected cells by the mean delta ct of the CVII siRNA control transfected cells, as previously described[15].

\section{Microarray expression analysis}

Microarray expression experiments were performed on $4 \times$ $44 \mathrm{~K}$ Agilent expression arrays (Agilent technologies) by hybridizing UPF1 siRNA transfected cells against non-specific CVII siRNA control transfected cells, according to the manufacturer's instructions. RNA quality was evaluated by generating an electropherogram on the Agilent Bioanalyzer 2100 using a RNA 6000 Nano-LabChip (Agilent Technologies). RNA integrity numbers (RIN) of $>9.0$ were considered as good quality RNA. Experiments were performed in dye-swap and in triplicate, resulting in six arrays per cell line. Images of the arrays were acquired using a microarray scanner G2505B (Agilent technologies) and image analysis was performed using feature extraction software version 9.5 (Agilent Technologies). The Agilent GE2-v5_95 protocol was applied using default settings.

All data pre-processing and analysis was performed using the R-Bioconductor package Limma[20]. First, a robust Edwards background correction was applied, followed by within-array and between-array normalization using loess and scale standardization, respectively. Differential expression between UPF1 siRNA transfected cells and non-specific CVII siRNA control transfected cells was assessed by use of a linear model, which accounts for a blocking factor, the day effect (triplicate). Moreover, the two-sample t-statistic modified for correlation between the two duplicates was used. Finally, p-values were adjusted for multiple testing using convential BenjaminiHochberg FDR correction.

Array CGH and microarray expression data can be assessed using the Gene Expression Omnibus (GEO) http://www.ncbi.nlm.nih.gov/geo/, under the accession number GSE12928.

\section{Mutation analysis}

From each RNA sample, $1 \mu \mathrm{g}$ was reverse transcribed to cDNA using oligo(dT) ${ }_{20}$ Primer (Invitrogen) with AMV reverse transcriptase (Promega, Leiden, NL). Mutation screening involved the entire coding region using primers overlapping the exon-exon boundaries. Each reaction was carried out in a total volume of $25 \mu \mathrm{l}$ containing $1 \mu \mathrm{l}$ of cDNA, 1,5 $\mu \mathrm{l} \mathrm{MgCl}_{2}(25 \mathrm{mM}), 2.5 \mu \mathrm{l}$ dNTPs (2 mM), 1.25 Units of Amplitaq Gold polymerase (Applied Biosystems), $2.5 \mu$ l GeneAmp ${ }^{\circledR} 10 \times$ PCR buffer II and $12.5 \mathrm{pmol}$ for each forward and reverse primer. When DMSO was added to the reaction, 2.5 Units of Amplitaq Gold polymerase was used. Amplification conditions were an initial denaturation step of 5 minutes at $94^{\circ} \mathrm{C}$ followed by 40 cycles of 30 seconds at $94^{\circ} \mathrm{C}, 30$ seconds at $55-57^{\circ} \mathrm{C}$ (depending on the primer pair), 30 seconds at $72^{\circ} \mathrm{C}$, and ending with 7 minutes at $72^{\circ} \mathrm{C}$. PCR products were evaluated in a $2 \%$ agarose gel. PCR products were purified using Shrimp Alkaline Posphatase and Exonuclease (SAP and EXO enzymes) (USB corporation, Cleveland, USA) to remove the phosphate groups from the excess dNTPs left over from the PCR reaction and to digest single stranded PCR primers into dNTPs by incubating for 30 minutes at $37^{\circ} \mathrm{C}$, followed by a 15 minute incubation at $80^{\circ} \mathrm{C}$ to inactivate the enzymes. Sequence reactions were performed in a total volume of $10 \mu \mathrm{l}$ containing $3.5 \mu \mathrm{l}$ purified PCR product, $2 \mu \mathrm{l}$ sequencing buffer $(5 \times), 0.5 \mu \mathrm{l}$ BigDye Terminater v3.1 mix (Applied Biosystems) and 10 pmol of each forward and reverse primer. Amplification was performed in 25 cycles of 30 seconds at $96^{\circ} \mathrm{C}, 15 \mathrm{sec}$ onds at $45^{\circ} \mathrm{C}$ and 4 minutes at $60^{\circ} \mathrm{C}$. Samples were precipitated by 0.1 volume NaAc (3 M; pH 5.3) and 2.5 volume ethanol. Sequencing of the PCR products was performed in $10 \mu \mathrm{l}$ deionised formamide (Applied Biosystems) on an ABI 3130 capillary sequencer (Applied Biosystems). Sequence analysis was carried out using the sequence Analysis 5.2 software (Applied Biosystems) and the Vector NTI software (Invitrogen). Details of the primer sequences, annealing temperatures and extra PCR conditions are given in Additional file 1.

Genomic DNA sequence analysis was performed with new designed primers by BaseClear (Leiden, The Netherlands). 


\section{Results \\ Array CGH profiles}

Array CGH profiles of the cell lines GP202 and IPA220 were obtained to detect the deleted areas potentially harbouring tumour suppressor genes. Array CGH profiles of the GP202 and IPA220 gastric cancer cell lines are shown in figure $1 \mathrm{~A}$ and $1 \mathrm{~B}$, respectively. A detailed overview of all gains and losses detected in these two cell lines is given in table 1 and 2.

\section{UPF I inhibition and expression array analysis}

Using the siRNA strategy, UPF1 expression was repressed by $>70 \%$ for the GP202 gastric cancer cell line (73\% 74\% and $71 \%$ for the biological replicates), and $>80 \%$ for the IPA220 gastric cancer cell line (82\%, 86\% and 84\% for the biological replicates).

Micoarray expression array analysis yielded 540 spotted oligonucleotides significantly upregulated (adjusted pvalues < 0.05 ) with a $\log _{2}$ ratio > 0.7 in the GP202 cells transfected with UPF1 siRNA compared to non-specific CVII siRNA control transfected cells. Of these, 164 oligonucleotides, representing 134 different genes, were located in deleted areas. The IPA220 UPF1 siRNA transfected cells showed 265 spotted oligonucleotides significantly upregulated (adjusted p-values $<0.05$ ) with a $\log _{2}$ ratio $>0.7$ compared to non-specific CVII siRNA control transfected cells. Of these, 50 different genes were located in deleted areas. Of these genes, we selected genes with only one known transcript according to ensemble http:// www.ensembl.org/Homo sapiens/index.html and genes of which no alternative splice patterns were known. This yielded a list of 10 candidate genes to be inactivated by nonsense mutation and deletion. The genes PLA2G4A, BMP5, MMP6, KNNMB4 and DYM were candidates for the GP202 gastric cancer cell line and the genes TXNL4B, FOXK1, PTPRJ, and SNN were candidates for the IPA220 gastric cancer cell line. The gene SLITRK6 was selected as a candidate gene for both gastric cancer cell lines, however only in the GP202 gastric cancer cell line this gene was located in a deleted area. In addition we selected two genes potentially inactivated by nonsense mutation which were located outside deleted areas, but showed high $\log _{2}$ ratios and no known splice variants (CSTA for the GP202 and INHBB for the IPA220 gastric cancer cell lines). Candidate genes, including their chromosomal location are presented in Table 3.

\section{Mutation analysis}

Of the 12 candidate genes, we successfully completed sequence analysis of 11 genes. After complete sequencing, KCNMB4, BMP5, DYM, TXNL4B, and SNN did not show any mutation. SLITRK 6 did not show a mutation in the UPF1 siRNA-transfected IPA220 and GP202 gastric cancer cells. However, in the UPF1 siRNA-transfected GP202 gas- tric cancer cells, the first 196 bp of the coding sequence was missing due to PCR failures. For the gene INHBB the first $413 \mathrm{bp}$ of the coding sequence was missing due to PCR failures but no mutation was detected in the remaining coding sequence. Due to the PCR failures, sequence analysis of these two genes was also performed on genomic DNA with new designed primers (BaseClear, Leiden, The Netherlands). Although sequencing of SLITRKG was successfully performed, no mutations were detected in this gene. Sequencing the genomic DNA of the gene $I N H B B$ was unsuccessful, consistent with the cDNA sequence of the gene.

In CSTA a heterozygous mutation was detected in both GP202 and IPA220 gastric cancer cells transfected with UPF1 siRNA, at position 298 (mRNA seq. NM005213.3) resulting in a $\mathrm{G}$ to $\mathrm{C}$ substitution, which in turn resulted in an amino acid change from GTA (Valine) to a ATA (Isoleucine) at position 57 of the CSTA protein. In PLA2G4A, a mutation was detected in the UPF1 siRNA-transfected GP202 gastric cancer cells, at position 1012 (mRNA seq NM_024420.1) resulting in a $\mathrm{C}$ to $\mathrm{T}$ substitution at position 303 of the protein, but this mutation did not result in a different amino acid (GAC to GAT (Aspartate)). In PTPRJ, three mutations were detected in the UPF1 siRNAtransfected IPA220 gastric cancer cells. The first mutation resulted in a $\mathrm{C}$ to A substitution at position 1183 (mRNA seq NM_002843.3), which resulted in a CAA (glutamine) to CCA (proline) amino acid change at position 276 of the PTPRJ protein. The second mutation resulted in a $\mathrm{G}$ to A substitution at position 1333 (mRNA seq NM002843.3), resulting in an amino acid change from CGA (Arginine) to CAA (Glutamine) at position 326 of the protein. The last mutation resulted in a $\mathrm{G}$ to $\mathrm{C}$ substitution at position 2972 (mRNA seq (NM_002843.3), resulting in CAG (Glutamine) to GAC (Aspartate) amino acid change at position 836 of the protein (Figure 2). Only the last mutation was detected in the GP202 gastric cancer cells transfected with UPF1 siRNA, but this was a heterozygous mutation.

Using the first primer set of MPP6, two bands were detected on the gel. After sequencing both bands we observed a 33 bp deletion before the coding start site in the shorter band which is suggestive for a splice variant since the exon-exon boundary is involved (Figure 3). No mutations were detected. An overview of the mutations detected in this study is presented in table 4 .

\section{Discussion}

Gastric cancer is a major cause of cancer death, but knowledge about the biology underlying gastric cancer development is still limited. Several chromosomal regions have been described to be frequently deleted in gastric cancer, but in most of the regions, no tumour suppressor genes 

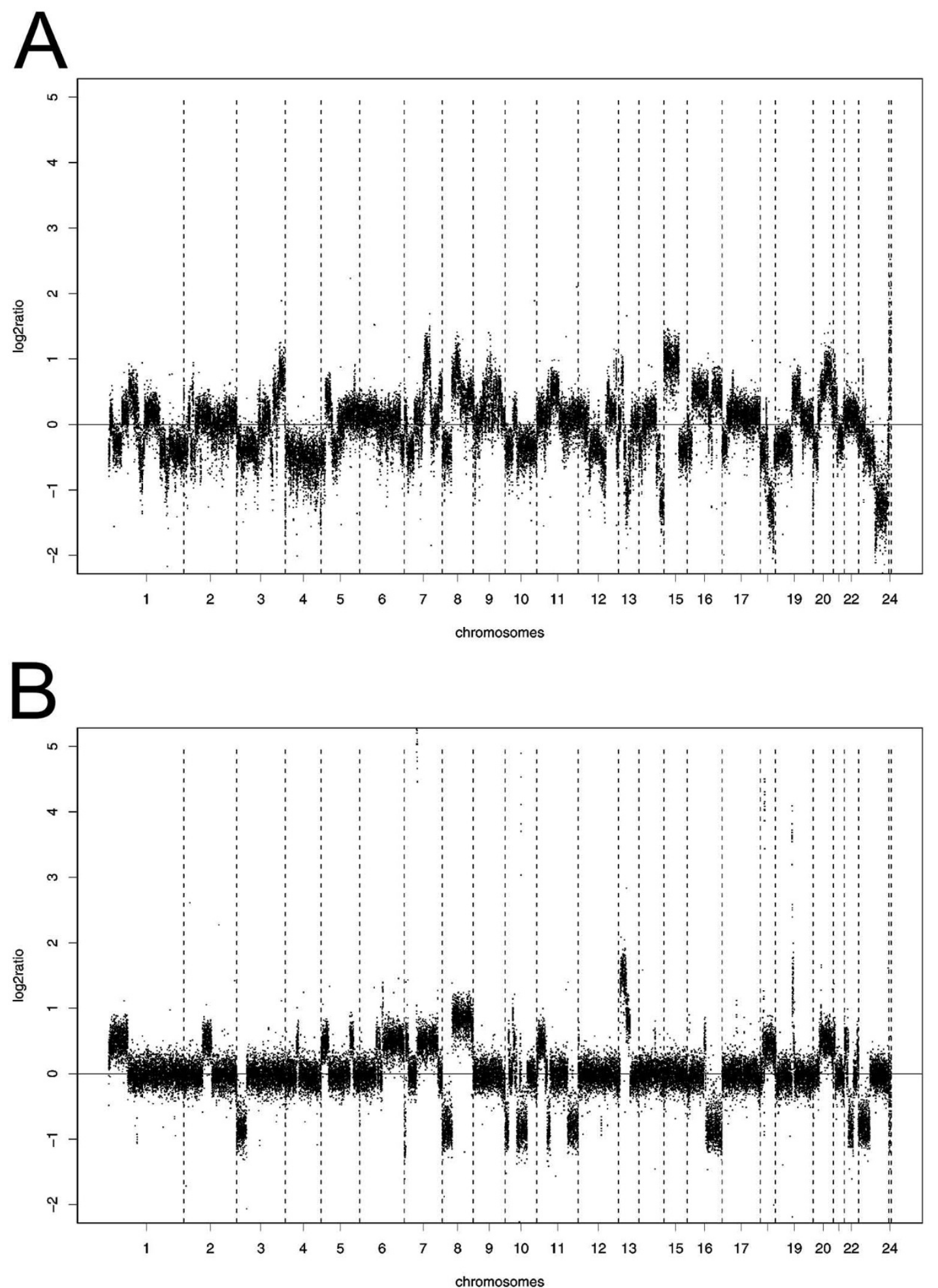

Figure I

DNA copy number profile obtained by array CGH analysis of the GP202 gastric cancer cell line. (A) and the IPA220 gastric cancer cell line (B). Normalised $\log _{2}$ tumour to normal ratios of every spot are presented sorted by position in chromosomal order (I-Y). Dashed-vertical lines - transition between the chromosomes. 
Table I: Overview of all chromosomal gains and losses detected in the gastric cancer cell line GP202

\begin{tabular}{|c|c|c|c|c|c|}
\hline \multicolumn{3}{|l|}{ Gains } & \multicolumn{3}{|l|}{ Losses } \\
\hline Cytoband & Start (bp) & Segment size $(\mathrm{Mb})$ & Cytoband & Start (bp) & Segment size $(\mathrm{Mb})$ \\
\hline & & & Ip36.33-I 36.32 & 604268 & 3.10 \\
\hline & & & $|p 36.2|-|p 35|$. & 14554092 & 18.26 \\
\hline$|p 32.3-| p 3 \mid .2$ & 51415638 & 17.20 & & & \\
\hline$|p 3| .|-| p 3||$. & 75490653 & 3.21 & & & \\
\hline \multirow[t]{5}{*}{$|p 31|-.\mid p 22.3$} & $844|448|$ & 2.76 & & & \\
\hline & & & $|p 22.2-| p \mid 3.3$ & 91093183 & 19.83 \\
\hline & & & Iq24.3-Iq44 & 167792143 & 77.63 \\
\hline & & & $2 p 25.3-2 p 23.3$ & 29193 & 24.75 \\
\hline & & & $2 p 23.1-2 p 22.2$ & 30171297 & 7.64 \\
\hline \multirow[t]{2}{*}{$2 p 22.2-2 p 22.1$} & 38068378 & 1.57 & & & \\
\hline & & & $2 p 22 . \mid-2 p 21$ & 39804095 & 2.17 \\
\hline \multirow[t]{9}{*}{$2 p 2|-2 p 2|$} & 42322892 & 1.85 & & & \\
\hline & & & $2 p 2|-2 p| 6.2$ & 44568947 & 8.24 \\
\hline & & & $2 p \mid 2-2 p 12$ & $7564 \mid 228$ & 7.06 \\
\hline & & & $2 q|4|-.2 q \mid 4.1$ & 114390667 & 2.40 \\
\hline & & & $2 q 24.1-2 q 24.1$ & $|555| 4824$ & 1.07 \\
\hline & & & $2 q 24.3-2 q 24.3$ & 166690618 & 1.25 \\
\hline & & & $2 q 32.1-2 q 32.2$ & 184949202 & 4.73 \\
\hline & & & $3 p 26.3-3 p \mid 1.1$ & 224727 & 87.69 \\
\hline & & & $3 q|1.2-3 q| 1.2$ & 95295727 & 3.77 \\
\hline \multirow[t]{2}{*}{$3 q|2.1-3 q| 2.2$} & $10002430 \mid$ & 1.70 & & & \\
\hline & & & $3 q 22.3-3 q 24$ & $140|458| 5$ & 8.85 \\
\hline $3 q 24-3 q 25.1$ & | 49729642 & 3.28 & & & \\
\hline \multirow[t]{2}{*}{$3 q 25.2-3 q 26.1$} & 156397505 & 6.15 & & & \\
\hline & & & $3 q 26.1-3 q 26.1$ & 162557800 & 6.25 \\
\hline $3 q 26.2-3 q 26.31$ & $|7034605|$ & 4.88 & & & \\
\hline \multirow[t]{3}{*}{$3 q 26.32-3 q 29$} & I7764040| & 20.35 & & & \\
\hline & & & $4 p 16.3-4 q 35.2$ & 62447 & 191.20 \\
\hline & & & $5 p|5.33-5 p| 4.1$ & 148243 & 29.04 \\
\hline $5 p|3.3-5 p| 2$ & 30636882 & 13.08 & & & \\
\hline \multirow[t]{3}{*}{$5 q|1.2-5 q| 2.1$} & $507 \mid 4334$ & 8.21 & & & \\
\hline & & & $5 q|2.3-5 q| 4.2$ & 65345185 & 17.43 \\
\hline & & & $5 q 31.3-5 q 31.3$ & 143269803 & 1.01 \\
\hline \multirow[t]{7}{*}{$5 q 33.3-5 q 34$} & 158674495 & 4.67 & & & \\
\hline & & & $6 p 21.2-6 p 21.2$ & 38554812 & 0.15 \\
\hline & & & $6 p|2.1-6 p| 2.1$ & 54055870 & 2.14 \\
\hline & & & $6 p 11.2-6 q 13$ & 58122432 & 12.68 \\
\hline & & & $6 q|5-6 q| 6.1$ & 91282705 & 5.81 \\
\hline & & & $6 q 16.3-6 q 21$ & 101156415 & 4.21 \\
\hline & & & $6 q 24.3-6 q 24.3$ & 147629943 & 0.12 \\
\hline \multirow[t]{3}{*}{$6 q 25.2-6 q 25.3$} & 155542493 & 0.97 & & & \\
\hline & & & $6 q 25.3-6 q 27$ & 156677778 & 14.13 \\
\hline & & & $7 p 21.3-7 p \mid 4.1$ & 8408484 & 33.10 \\
\hline \multirow[t]{3}{*}{$7 p|| .2-7 p|| .2$} & 54921296 & 0.57 & & & \\
\hline & & & $7 q|1.2|-7 q \mid 1.22$ & 65833193 & 4.96 \\
\hline & & & $7 q|| .23-7 q|| .23$ & $768 \mid 8583$ & 0.16 \\
\hline $7 q 21.13-7 q 31.1$ & 90482514 & 19.64 & & & \\
\hline \multirow[t]{3}{*}{ 7q31.I-7q3।.I } & 110637986 & 1.28 & & & \\
\hline & & & 7q31.І-7q31.2 & 113074003 & 2.15 \\
\hline & & & $7 q 31.33-7 q 31.33$ & $|249| 267 \mid$ & 0.76 \\
\hline $7 q 34-7 q 35$ & 142863066 & 0.23 & & & \\
\hline \multirow[t]{3}{*}{$7 q 35-7 q 36.3$} & $|47| \mid 2584$ & 11.48 & & & \\
\hline & & & $8 p 23.3-8 p 23.1$ & 181530 & 11.15 \\
\hline & & & $8 p 23 .|-8 p| 1.21$ & 12627630 & 29.40 \\
\hline $8 p \mid 1.21-8 q 21.3$ & 42137357 & 49.48 & & & \\
\hline $8 q 22.1-8 q 22.3$ & 95005574 & 9.49 & & & \\
\hline $8 q 24.11-8 q 24.3$ & 117851748 & 28.40 & & & \\
\hline
\end{tabular}


Table I: Overview of all chromosomal gains and losses detected in the gastric cancer cell line GP202 (Continued)

\begin{tabular}{|c|c|c|c|c|c|}
\hline \multirow[t]{3}{*}{$9 p 24.3-9 p 24.2$} & 204367 & 3.94 & & & \\
\hline & & & $9 p 23-9 p 22.3$ & 9335062 & 5.76 \\
\hline & & & $9 p 21.1-9 p 21.1$ & 28203365 & 2.53 \\
\hline $9 q 13-9 q 21.13$ & 68264900 & 4.61 & & & \\
\hline $9 q 21.13-9 q 21.31$ & 74400503 & 5.06 & & & \\
\hline $9 q 21.33-9 q 22.1$ & 85372508 & 2.87 & & & \\
\hline $9 q 22.2-9 q 22.31$ & 89232280 & 2.91 & & & \\
\hline $9 q 22.31-9 q 22.32$ & 93160028 & 1.30 & & & \\
\hline $9 q 22.33-9 q 31.1$ & 97586481 & 3.58 & & & \\
\hline $9 q 31.1-9 q 31.1$ & $1043 \mid 4825$ & 0.46 & & & \\
\hline $9 q 31.3-9 q 32$ & 110265680 & 3.46 & & & \\
\hline $9 q 33.1-9 q 33.2$ & 115059550 & 7.40 & & & \\
\hline $9 q 33.2-9 q 33.3$ & 122895073 & 0.42 & & & \\
\hline \multirow[t]{3}{*}{$9 q 33.3-9 q 34.11$} & 126436029 & 3.69 & & & \\
\hline & & & I0p|5.3-10p||.22 & 138206 & 34.13 \\
\hline & & & $10 q 21.1-10 q 26.3$ & 54480789 & 80.81 \\
\hline||$p|| .2-|| p|| .2$ & 43422214 & 1.84 & & & \\
\hline \multirow[t]{5}{*}{||$q|2|-.|| q \mid 3.4$} & 57256449 & 13.13 & & & \\
\hline & & & ||$q|4.3-||q| 4.3$ & 87970040 & 0.76 \\
\hline & & & ||$q|4.3-||q| 4.3$ & 89525497 & 0.05 \\
\hline & & & | |q21-I |q22.| & 96058479 & 3.39 \\
\hline & & & $12 q 12-12 q 22$ & 37052371 & 55.79 \\
\hline $12 q 23.1-12 q 23.3$ & 96894351 & 6.93 & & & \\
\hline $12 q 24.23-12 q 24.23$ & 117761811 & $0.6 \mathrm{I}$ & & & \\
\hline \multirow[t]{2}{*}{$|2 q 24.3|-|2 q 24.3|$} & $12197 \mid 290$ & 1.03 & & & \\
\hline & & & $12 q 24.31-12 q 24.33$ & 123020939 & 9.36 \\
\hline \multirow[t]{9}{*}{$13 q|2.2-13 q| 3.1$} & 27392825 & 5.14 & & & \\
\hline & & & $13 q 13.3-13 q 21.33$ & 34631933 & 36.49 \\
\hline & & & $13 q 31.1-13 q 31.3$ & 79911534 & 13.43 \\
\hline & & & $|4 q||.2-| 4 q|| .2$ & $1936505 \mid$ & 2.79 \\
\hline & & & $|4 q| 1.2-14 q \mid 2$ & 2254567 I & 6.72 \\
\hline & & & $|4 q| 3.3-|4 q 2| . \mid$ & 36741208 & 0.35 \\
\hline & & & $|4 q 21.1-| 4 q 2 \mid .2$ & 40137052 & 3.71 \\
\hline & & & $|4 q 2| .2-|4 q 2| .3$ & 45739681 & 3.13 \\
\hline & & & $14 q 31.1-14 q 32.33$ & 78503451 & 27.83 \\
\hline \multirow[t]{3}{*}{$15 q \mid 1.2-15 q 24.1$} & 19109124 & 52.29 & & & \\
\hline & & & $15 q 24.1-15 q 26.3$ & $7 \mid 444303$ & 28.72 \\
\hline & & & $|6 p| 3.3-|6 p| 3.3$ & 1339391 & 3.35 \\
\hline \multirow[t]{2}{*}{$16 p|3.3-16 p| 2.3$} & 5565717 & 13.83 & & & \\
\hline & & & $16 p|2.3-16 p| 2.3$ & 19426488 & 0.04 \\
\hline \multirow[t]{2}{*}{$16 p \mid 2.3-16 q 21$} & 19493912 & 38.95 & & & \\
\hline & & & $16 q 22.1-16 q 22.1$ & 66730760 & 1.00 \\
\hline $16 q 22.1-16 q 23.1$ & 67757442 & 9.01 & & & \\
\hline \multirow[t]{2}{*}{$16 q 23.1-16 q 24.3$} & 77573211 & 11.08 & & & \\
\hline & & & $17 p|3.3-17 p| 3.1$ & 48539 & 7.48 \\
\hline \multirow[t]{4}{*}{$|7 q|||-.|7 q| \mid .2$} & 22335103 & 1.75 & & & \\
\hline & & & $|8 p||.32-18 q| 2.1$ & 170229 & 30.01 \\
\hline & & & $18 q 12.3-18 q 23$ & 36319629 & 39.76 \\
\hline & & & $19 p / 3.3-19 q 12$ & 232080 & 33.93 \\
\hline \multirow[t]{3}{*}{$|9 q| 2-19 q|3.3|$} & 36336102 & 12.74 & & & \\
\hline & & & $19 q|3.32-19 q| 3.32$ & 52132977 & 0.56 \\
\hline & & & $20 p|3-20 p| 2.1$ & 18580 & $|4.5|$ \\
\hline $20 p|2.1-20 p| 2.1$ & 14772372 & 1.30 & & & \\
\hline $20 p|| .2|-20 q| 3.33$ & 24262140 & 38.10 & & & \\
\hline \multirow[t]{2}{*}{$2|q 21|-.2|q 2| .3$} & |743496| & 11.95 & & & \\
\hline & & & $2|q 21.3-2| q 22.3$ & 29452714 & 16.38 \\
\hline
\end{tabular}


Table 2: Overview of all chromosomal gains and losses detected in the gastric cancer cell line IPA220.

\begin{tabular}{|c|c|c|c|c|c|}
\hline \multicolumn{3}{|l|}{ Gains } & \multicolumn{3}{|l|}{ Losses } \\
\hline Cytoband & Start (bp) & Segment size $(\mathrm{Mb})$ & Cytoband & Start (bp) & Segment size $(\mathrm{Mb})$ \\
\hline $1 p 33-1 p 36.33$ & 1532086 & 45.95 & & & \\
\hline \multirow[t]{2}{*}{$1 p 33-1 p 33$} & 48905659 & 0.05 & & & \\
\hline & & & Ip22.3-Ip22.3 & 85435027 & 0.06 \\
\hline $2 q 22.1-2 q \mid I . I$ & 95057834 & 45.61 & & & \\
\hline \multirow[t]{3}{*}{$2 q 33.1-2 q 33.1$} & 200167066 & 0.43 & & & \\
\hline & & & $3 p 26.3-3 p 22.1$ & 224727 & 40.68 \\
\hline & & & $4 p|6.3-4 p| 6.3$ & 62447 & 1.83 \\
\hline $4 q|3.3-4 q| 3.1$ & 60036497 & 14.87 & & & \\
\hline $5 p|2-5 p| 5.33$ & 148243 & 43.37 & & & \\
\hline \multirow[t]{2}{*}{$5 q 33.2-5 q 31.3$} & 141986337 & 12.82 & & & \\
\hline & & & 6p25.3-6p25.3 & 204528 & 0.03 \\
\hline $6 p 12.3-6 p 21.1$ & 43716420 & 5.79 & & & \\
\hline $6 q|2-6 p| 2.1$ & 56790132 & 12.18 & & & \\
\hline \multirow{2}{*}{$6 q 27-6 q 14.1$} & 80423355 & 90.39 & & & \\
\hline & & & $7 p 22.3-7 p 22.1$ & 149268 & 4.55 \\
\hline $7 p 21.1-7 p 22.1$ & 4874872 & 14.88 & & & \\
\hline \multirow[t]{2}{*}{$7 q 34-7 p 12.1$} & 53246250 & 86.37 & & & \\
\hline & & & $8 p 23.3-8 p \mid 1.21$ & 181530 & 42.99 \\
\hline \multirow{3}{*}{$8 q 24.3-8 q \mid \mathrm{l} .1$} & 47062121 & 99.19 & & & \\
\hline & & & $9 q 34.2-9 q 34.3$ & 133008166 & 5.28 \\
\hline & & & $10 p 15.3-10 p \mid 3$ & 138206 & 16.20 \\
\hline $10 p|2.33-10 p| 3$ & 16543648 & 1.39 & & & \\
\hline $10 q|| .22-10 p|| .22$ & 33177446 & 13.39 & & & \\
\hline \multirow[t]{2}{*}{$10 q|1.23-10 q| 1.23$} & 51219561 & 0.04 & & & \\
\hline & & & $10 q 21.1-10 q 22.1$ & 53701099 & 18.43 \\
\hline \multirow[t]{2}{*}{$10 q 22.1-10 q 22.1$} & 74316662 & 0.24 & & & \\
\hline & & & $10 q 22.1-10 q 22.2$ & 74569446 & 0.95 \\
\hline \multirow[t]{4}{*}{$10 q 22.2-10 q 22.2$} & 75567726 & 0.57 & & & \\
\hline & & & $10 q 22.2-10 q 22.2$ & 76194936 & 0.41 \\
\hline & & & $10 q 22.2-10 q 24.2$ & 77212707 & 23.02 \\
\hline & & & $10 q 26.3-10 q 26.3$ & 133641790 & 1.65 \\
\hline \multirow[t]{2}{*}{ IIp|4.I-IIp|5.5 } & 2389958 & 27.82 & & & \\
\hline & & & ||$p|2-||p||| 2$. & 39023903 & 11.61 \\
\hline \multirow[t]{4}{*}{||$q|3|-.|| q \mid 3.1$} & 65527252 & 0.02 & & & \\
\hline & & & ||$q|4.3-1| q \mid 4.3$ & 88320337 & 0.38 \\
\hline & & & I I q22.3-I I q23.3 & 103942362 & 13.29 \\
\hline & & & IIq23.3-1 Iq25 & 117574530 & 16.38 \\
\hline$|2 p| 3.33-12 p \mid 3.33$ & |47|57| & 0.32 & & & \\
\hline $13 q 21.31-13 q 12.13$ & 24807238 & 37.57 & & & \\
\hline \multirow[t]{3}{*}{$14 q 24.3-14 q 24.3$} & 74237320 & 1.26 & & & \\
\hline & & & $\mid 4 q 32.33-14 q 32.33$ & 103705675 & 2.24 \\
\hline & & & $16 p|3.3-16 p| 3.3$ & 258880 & 1.09 \\
\hline \multirow[t]{3}{*}{$16 q|2.2-16 q| 2.1$} & 48880404 & 2.95 & & & \\
\hline & & & $16 q 12.2-16 q 22.1$ & 53523174 & 12.50 \\
\hline & & & $16 q 22.1-16 q 24.3$ & 66132070 & 22.52 \\
\hline $17 q 21.31-17 q 21.31$ & 41566540 & 0.06 & & & \\
\hline$|8 q| 1.2-|8 p| \mid .22$ & 10662792 & 7.80 & & & \\
\hline & & & $|8 q||.2-| 8 q|| .2$ & 20896260 & 0.38 \\
\hline $18 q 23-|8 q| 1.2$ & 21531881 & 53.70 & & & \\
\hline $18 q 23-18 q 23$ & 75803559 & 0.28 & & & \\
\hline $19 p|3.3-19 p| 3.3$ & 232080 & 0.75 & & & \\
\hline $19 q 13.12-19 q 12$ & 34074193 & 6.56 & & & \\
\hline $20 p|| .21-20 p|| .22$ & 21329267 & 4.35 & & & \\
\hline $20 q|3.33-20 q||.2|$ & 29352138 & 33.01 & & & \\
\hline $2|q 2| .|-2| q|| .2$ & 13926078 & 6.84 & & & \\
\hline & & & $21 \mathrm{q} 22.3-21 \mathrm{q} 22.3$ & 45354820 & 1.07 \\
\hline $22 q|I .22-22 q| I . \mid$ & | 4433473 & 7.35 & & & \\
\hline $22 q|2|-.22 q \mid 1.23$ & 23692593 & 2.23 & & & \\
\hline & & & $22 q|2.1-22 q| 3.1$ & 26016519 & 10.56 \\
\hline & & & $22 q|3.1-22 q| 3.1$ & 37683612 & 0.03 \\
\hline $22 q|3.33-22 q| 3.3 \mid$ & 44867938 & 3.71 & & & \\
\hline
\end{tabular}


have been described yet. Using the GINI strategy in combination with array CGH, we aimed to identify tumour suppressor genes inactivated by nonsense mutation and deletion in gastric cancer cell lines.

The first GINI strategies used a translation inhibitor to block the NMD pathway. By using translation inhibitors, the half-lives of many mRNAs are increased making it difficult to identify genes of which mRNA is increased due to the existence of a PTC[21]. In an attempt to improve detection of changes in decay rates, actinomycin D treatment, which stops initiation of mRNA synthesis, has been combined with translation inhibitors[17]. This strategy proved not to be as efficient as initially thought, probably due to side-effects of the drugs which have been suggested to include stabilization of the transcriptome, resulting in protection of the transcripts from degradation. In addition, using drug treatment, an overall stress response is induced resulting in upregulation of many transcripts $[21,22]$. We have previously used a combination of emitine and actinomycin $\mathrm{D}$ treatment to inhibit the NMD machinery in three colorectal cancer cell lines, two microsatellite stable (HT29 and colo205) and one microsatellite instable (RKO). Sequence analysis of the candidate genes did not lead to the identification of any truncation mutation (data not shown).

In the present study, we used siRNAs directly targeting UPF1 which plays a central role in the NMD machinery. This approach was thought to result in less false positive genes compared to chemical translation inhibitors $[15,22]$. However, as the present study indicated, in our hands this method also resulted in multiple false positive candidate genes.

Nonetheless, the GINI approach, using drug translation inhibitors in combination with transcription blockers, has been successfully applied in prostate and colon cancer cell lines[17,23]. Also a different GINI approach (GINI2), using caffeine for NMD inhibition, has been successfully applied in the identification of bi-allelic inactivating mutations[24]. Blocking the NMD machinery using the siRNA strategy was also successful in detecting genes carrying PTCs in colorectal cancer cell lines[15]. However, in all these studies only cancer cell lines with microsatellite instability were analyzed, increasing the chance of success as microsatellite instable cell lines present, due to their phenotype, a high frequency of frameshift mutations leading to PTCs. To our knowledge, this is the first study describing the GINI technology in microsatellite stable gastric cancer cell lines blocking the NMD mechanism by siRNAs targeting UPF1. After sequencing the mRNA transcripts of the putative candidate genes, we did not detect nonsense mutations. The fact that the cell lines used in this study are not microsatellite instable may justify the lack of success on finding genes harbouring premature PTCs. However, the technique should also be applicable on microsatellite stable cancer cell lines as shown by Pinyol et al[25]. In their study, five mantle cell lymphoma cell lines were examined which may result in a more accurate and stringent selection of candidate genes compared to our data analysis in which we only used two cell lines.

Although no nonsense mutations were found in this study, we did detect silent or missense mutations in three genes. A silent mutation was detected in the gene PLA2G4A at position 303 of the protein. This polymorphism has not been previously described. A missense mutation was detected in the CTSA gene at position 57 of the protein changing a Valine into an Isoleucine. In the gene PTPRJ, three missense mutations were detected in IPA220 gastric cancer cell line. The mutations Gln276Pro and Arg326Gln in exons 5 and 6, respectively, have been described before as being polymorphisms[26]. To our knowledge, the third mutation, Glu836Asp, in exon 13, has not been previously described, thus the biological consequence, if any, is not clear. Loss of heterozygosity (LOH) of PTPRJ has been detected in breast, lung and

Table 3: List of 12 candidate genes putatively inactivated by nonsense mutation, including their chromosomal location, the cell line where it was identified and a short description of the gene.

\begin{tabular}{|c|c|c|c|}
\hline Gene & Location & Cell line & Description \\
\hline PLA2G4A & $\mid q 31.1$ & GP202 & phospholipase A2, group IVA \\
\hline INHBB & $2 q \mid 4,2$ & IPA220 & Inhibin, beta B \\
\hline CSTA & $3 q 21.1$ & GP202 & Cystatin A \\
\hline BMP5 & $6 p 12.1$ & GP202 & Bone morphogenetic protein 5 \\
\hline MMP6 & $7 p 15.3$ & GP202 & membrane protein, palmitoylated 6 (MAGUK p55 subfamily member 6 ) \\
\hline FOXKI & $7 p 22.1$ & IPA220 & Forkhead box KI \\
\hline PTPRJ & ||$p|| .2$ & IPA220 & Protein tyrosine phosphatase, receptor type J \\
\hline KCNMB4 & $12 q 15$ & GP202 & Potassium channel, calcium-activated, large conductance, subfamily $M$, beta member 4 \\
\hline SLITRK6 & $|3 q 3| . \mid$ & GP202, IPA220 & SLIT and NTRK-like family, member 6 \\
\hline SNN & $16 p 13$ & IPA220 & stannin \\
\hline TXNL4B & $16 q 22.2$ & IPA220 & Thioredoxin-like 4B \\
\hline DYM & $18 q 21.1$ & GP202 & dymecelin \\
\hline
\end{tabular}



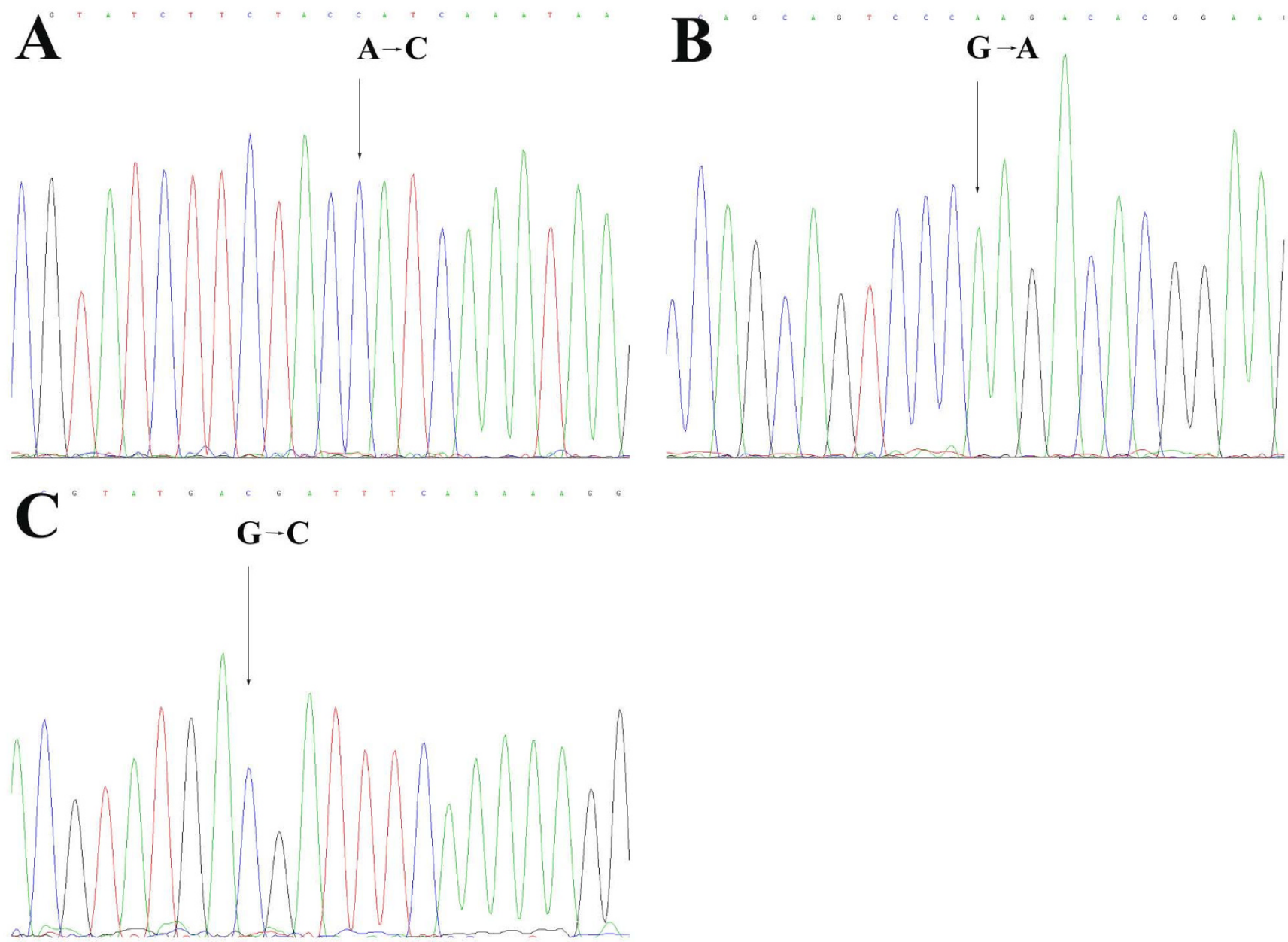

Figure 2

Mutations analysis of PTPRJ in the IPA220 siRNA transfected cells yielded three polymorphisms, AI I83C on exon 5 (A), GI333A on exon 6 (B) and G2972C on exon I3 (C).

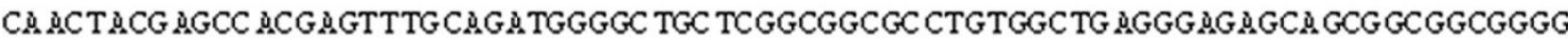

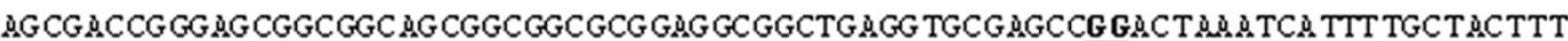 מ H ג TT TẢ AGCAGCTA

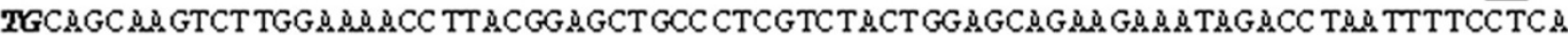

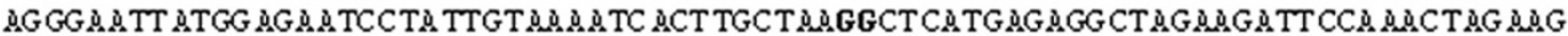

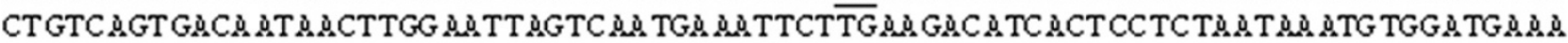

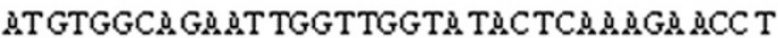

Figure 3

First part of the mRNA sequence of the MMP6 gene. The sequence in bold represents the missing sequence in the smaller PCR product, located upstream of the start codon. Bold and underlined nucleotides represent the exon-exon boundaries The start codon ATG is indicated in bold and italic. 
Table 4: Overview of mutations detected in the candidate genes

\begin{tabular}{lccc}
\hline Gene & Nucleotide & Amino acid & Exon \\
\hline CSTA & G298C & Val57lle & 2 \\
PLA2G4A & CI012T & Asp303Asp & 15 \\
PTPRJ & Al183C & Gln276Pro & 5 \\
& GI333A & Arg326Gln & 6 \\
& G2972C & Glu836Asp & 13 \\
\hline
\end{tabular}

colon cancers and expression has been shown to induce differentiation and to inhibit growth of breast cancer cells, indicating a function as tumour suppressor gene [26-28]. Since we detected missense mutations of this gene in the gastric cancer cell lines analyzed, it gives the indication that PTPRJ might play a role as tumour suppressor gene in gastric cancer, however, apparently not by inactivation by nonsense

mutation.

One explanation why our strategy of GINI combined with DNA copy number profiling failed to detect new tumour suppressor genes with nonsense mutations could be that these nonsense mutations are less common than expected. Indeed, recent massive sequencing studies have identified that many cancer related genes often are mutated in only low frequencies, while alternative mechanisms of inactivation like promoter hypermethylation are much more common[29,30].

An important point is why siRNA inhibition of UPF1 generates so many false positive hits. Besides a crucial role of UPF1 in RNA degradation pathways, the gene also plays a role in DNA replication during the $S$ phase of the cell cycle, and has been shown to be involved in DNA metabolism. UPF1 depletion causes cells to arrest in the S phase and those cells are able to initiate but not complete DNA replication. UPF1 depleted cells have been shown to harbour increased chromatid and chromosome breaks leading to chromosomal aberrations[31,32]. In addition, UPF1 has been shown to promote the rate and efficiency of translation of normal mRNAs in mammalian cells[33]. Translation termination in UPF1 mutants was shown to be dependent on the sequence context. Efficient translation termination was observed when UCC (Serine) was located upstream and GCA (Alanine) was located downstream of the PTC. Location of CAA (Glutamine) on either side of the PTC resulted in up to 100 fold reduction in efficiency of translation termination[34]. We could speculate that by inhibiting UPF1 by siRNAs also mRNAs without PTCs are not efficiently translated into proteins, and consequently negative feedback loops are not activated, causing the cell to produce more mRNAs due to lack of functional proteins essential for the cell. This in turn can cause accumulation of mRNA resulting in false positive genes. Another hypothesis possibly contributing to the false positive genes found in our analysis can involve the coding sequence surrounding the PTCs which can determine the efficiency of the NMD machinery. Also, NMD downregulates wild-type transcripts and regulates the expression of many physiological transcripts[16]. Physiological substrates for NMD include transcripts with alternative splice variants. For this reason we excluded the genes with multiple known splice variants as candidate genes carrying a PTC, thereby limiting the rate of false positive candidate genes. Nonetheless, among the genes with one known transcript, the GINI technology still yielded many false positive candidate genes.

Finally, although $70-80 \%$ depletion of UPF1 is thought to be sufficient for inhibiting the NMD machinery both in microsatellite instable cell lines[15] as well as in microsatellite stable gastric cancer cell lines[35], with correlation with downregulation of the UPF1 protein, we cannot exclude the possibility that in this case the treatment was insufficient.

Despite the fact that we did not successfully detect genes carrying a PTC using the GINI technology, we cannot rule out that the gene INHBB did not harbour a PTC since we were unable to sequence the full length of the gene. However, all other candidate genes were successfully sequenced without detecting a PTC. Therefore, we still believe that the siRNA mediated inhibition of the NMD machinery yields many false positive candidate genes.

In summary, we aimed to find candidate genes inactivated by nonsense mutation and deletion in the gastric cancer cell lines to further validate our results of DNA copy number profiling and expression analysis in primary gastric cancers. Although the GINI technology theoretically is a powerful method for identifying candidate tumour suppressor genes inactivated by nonsense mutations, siRNA mediated inhibition of the NMD machinery yielded false positive results in our hands. The GINI technique might be optimized by using a vector containing multiple small hairpin RNAs (shRNAs) that can silence multiple target sites simultaneously, to more effectively knockdown the NMD system[36]. Moreover, applying this strategy on 
multiple cell lines might be a more conservative approach applicable for selecting candidate genes, thereby contributing to less false positive test results. On the other hand, the discovery of new tumour suppressor genes inactivated by nonsense mutation by means of GINI may be redundant in the near future due to the emerging of the nextgeneration technologies in which the complete genome can be analyzed by massive parallel sequencing[37].

\section{Conclusion}

The GINI technology by means of siRNA mediated inhibition of the NMD machinery in gastric cancer cell lines yielded false positive results in our hands.

\section{Abbreviations}

NMD: nonsense-mediated decay; GINI: gene identification by nonsense mediated decay inhibition; CGH: comparative genomic hybridization; siRNA: small interfering RNA; shRNA: small hairpin RNA; PTC: premature termination codon; FDR: false discovery rate.

\section{Competing interests}

The authors declare that they have no competing interests.

\section{Authors' contributions}

TB performed the cell culture, siRNA transfections, RNA isolations, RT-PCR experiments and wrote the manuscript, MT performed the microarray experiments and sequence analysis, JE-B optimized all conditions for the cell culture, siRNA transfections and RT-PCR experiments, as well as guidance of the transfection procedure, AD provided the facilities to do the siRNA transfections and helped in coordinating the work, MvdW performed the microarray expression data analysis, BY provided the facilities for the microarrays experiments, GM and BC conceived and coordinated the study and helped in critically reviewing the manuscript. All authors read and approved the final manuscript.

\section{Additional material}

\section{Additional file 1}

Primer sequences and conditions of the candidate genes. This table shows the details of the primer sequences, annealing temperatures and extra PCR conditions of the candidate genes, inactivated by nonsense mutation and deletion, selected for mutation analysis. Genes sequenced for mutation analysis are shown in bold. Temp - annealing temperature. Click here for file

[http://www.biomedcentral.com/content/supplementary/17558794-2-39-S1.doc]

\section{Acknowledgements}

We thank Prof. Dr. R. Seruca for providing the gastric cancer cell lines. This work was financially supported by the Dutch Cancer Society, grant KWF2004-305I.

\section{References}

I. Lengauer C, Kinzler KW, Vogelstein B: Genetic instabilities in human cancers. Nature 1998, 396:643-649.

2. Buffart T, Carvalho B, Hopmans E, Brehm V, Klein-Kranenbarg E, Schaaij-Visser T, Eijk P, van Grieken N, Ylstra B, Velde CJ van de, et al.: Gastric cancers in young and elderly patients show different genomic profiles. J Pathol 2007, 2 I I:45-5 I.

3. Guan XY, Fu SB, Xia JC, Fang Y, Sham JS, Du BD, Zhou H, Lu S, Wang $B Q$, Lin $Y Z$, et al:: Recurrent chromosome changes in 62 primary gastric carcinomas detected by comparative genomic hybridization. Cancer Genet Cytogenet 2000, I 23:27-34.

4. Hidaka S, Yasutake T, Kondo $M$, Takeshita $H$, Yano $H$, Haseba $M$, Tsuji T, Sawai T, Nakagoe T, Tagawa Y: Frequent gains of $20 q$ and losses of $18 \mathrm{q}$ are associated with lymph node metastasis in intestinal-type gastric cancer. Anticancer Res 2003, 23:3353-3357.

5. Kimura Y, Noguchi T, Kawahara K, Kashima K, Daa T, Yokoyama S: Genetic alterations in 102 primary gastric cancers by comparative genomic hybridization: gain of $20 \mathrm{q}$ and loss of $\mathbf{1 8 q}$ are associated with tumor progression. Mod Pathol 2004, I 7:1328-1337.

6. Queimado L, Seruca R, Costa-Pereira A, Castedo S: Identification of two distinct regions of deletion at $\mathbf{6 q}$ in gastric carcinoma. Genes Chromosomes Cancer 1995, I 4:28-34.

7. Sakakura C, Mori T, Sakabe T, Ariyama Y, Shinomiya T, Date K, Hagiwara A, Yamaguchi T, Takahashi T, Nakamura Y, et al:: Gains, losses, and amplifications of genomic materials in primary gastric cancers analyzed by comparative genomic hybridization. Genes Chromosomes Cancer 1999, 24:299-305.

8. Takada H, Imoto I, Tsuda H, Sonoda I, Ichikura T, Mochizuki H, Okanoue T, Inazawa J: Screening of DNA copy-number aberrations in gastric cancer cell lines by array-based comparative genomic hybridization. Cancer Sci 2005, 96: 100-I I0.

9. van Grieken NC, Weiss MM, Meijer GA, Hermsen MA, Scholte GH, Lindeman J, Craanen ME, Bloemena E, Meuwissen SG, Baak JP, et al.: Helicobacter pylori-related and -non-related gastric cancers do not differ with respect to chromosomal aberrations. J Pathol 2000, 192:301-306.

10. Weiss MM, Kuipers EJ, Postma C, Snijders AM, Siccama I, Pinkel D, Westerga J, Meuwissen SG, Albertson DG, Meijer GA: Genomic profiling of gastric cancer predicts lymph node status and survival. Oncogene 2003, 22:1872-1879.

II. Weiss MM, Kuipers EJ, Postma C, Snijders AM, Pinkel D, Meuwissen SG, Albertson D, Meijer GA: Genomic alterations in primary gastric adenocarcinomas correlate with clinicopathological characteristics and survival. Cell Oncol 2004, 26:307-3I7.

12. Carvalho B, Seruca R, Carneiro F, Buys CH, Kok K: Substantial reduction of the gastric carcinoma critical region at 6 q 16.3q23. I. Genes Chromosomes Cancer 1999, 26:29-34.

13. Lykke-Andersen J, Shu MD, Steitz JA: Human Upf proteins target an mRNA for nonsense-mediated decay when bound downstream of a termination codon. Cell 2000, I03:II2I-II3I.

14. Noensie EN, Dietz HC: A strategy for disease gene identification through nonsense-mediated mRNA decay inhibition. Nat Biotechnol 2001, 19:434-439.

15. El-Bchiri J, Buhard O, Penard-Lacronique V, Thomas G, Hamelin R, Duval A: Differential nonsense mediated decay of mutated mRNAs in mismatch repair deficient colorectal cancers. Hum Mol Genet 2005, I 4:2435-2442.

16. Mendell JT, Sharifi NA, Meyers JL, Martinez-Murillo F, Dietz HC: Nonsense surveillance regulates expression of diverse classes of mammalian transcripts and mutes genomic noise. Nat Genet 2004, 36:1073-1078.

17. Huusko P, Ponciano-Jackson D, Wolf M, Kiefer JA, Azorsa DO, Tuzmen S, Weaver D, Robbins C, Moses T, Allinen M, et al.: Nonsensemediated decay microarray analysis identifies mutations of EPHB2 in human prostate cancer. Nat Genet 2004, 36:979-983.

18. Gartner F, David L, Seruca R, Machado JC, Sobrinho-Simoes M: Establishment and characterization of two cell lines derived 
from human diffuse gastric carcinomas xenografted in nude mice. Virchows Arch 1996, 428:91-98.

19. Buffart TE, Israeli D, Tijssen M, Vosse SJ, Mrsic A, Meijer GA, Ylstra B: Across array comparative genomic hybridization: a strategy to reduce reference channel hybridizations. Genes Chromosomes Cancer 2008, 47:994-1004.

20. Smyth GK: Linear models and empirical bayes methods for assessing differential expression in microarray experiments. Stat Appl Genet Mol Biol 2004, 3:

21. Ross j: A hypothesis to explain why translation inhibitors stabilize mRNAs in mammalian cells: mRNA stability and mitosis. Bioessays 1997, 19:527-529.

22. Wolf M, Edgren H, Muggerud A, Kilpinen S, Huusko P, Sorlie T, Mousses $\mathrm{S}$, Kallioniemi O: NMD microarray analysis for rapid genome-wide screen of mutated genes in cancer. Cell Oncol 2005, 27:169-173.

23. lonov Y, Nowak N, Perucho M, Markowitz S, Cowell JK: Manipulation of nonsense mediated decay identifies gene mutations in colon cancer Cells with microsatellite instability. Oncogene 2004, 23:639-645.

24. Ivanov I, Lo KC, Hawthorn L, Cowell JK, lonov Y: Identifying candidate colon cancer tumor suppressor genes using inhibition of nonsense-mediated mRNA decay in colon cancer cells. Oncogene 2007, 26:2873-2884.

25. Pinyol M, Bea S, Pla L, Ribrag V, Bosq J, Rosenwald A, Campo E, Jares $P$ : Inactivation of RBI in mantle-cell lymphoma detected by nonsense-mediated mRNA decay pathway inhibition and microarray analysis. Blood 2007, 109:5422-5429.

26. Ruivenkamp CA, van WT, Zanon C, Stassen AP, Vlcek C, Csikos T, Klous AM, Tripodis N, Perrakis A, Boerrigter L, et al.: Ptprj is a candidate for the mouse colon-cancer susceptibility locus Sccl and is frequently deleted in human cancers. Nat Genet 2002, 3 I:295-300.

27. Ruivenkamp C, Hermsen M, Postma C, Klous A, Baak J, Meijer G, Demant P: LOH of PTPRJ occurs early in colorectal cancer and is associated with chromosomal loss of $|8 q| 2-2 \mid$. Oncogene 2003, 22:3472-3474.

28. Keane MM, Lowrey GA, Ettenberg SA, Dayton MA, Lipkowitz S: The protein tyrosine phosphatase DEP-I is induced during differentiation and inhibits growth of breast cancer cells. Cancer Res 1996, 56:4236-4243.

29. Chan TA, Glockner S, Yi JM, Chen W, Van NL, Cope L, Herman JG, Velculescu V, Schuebel KE, Ahuja N, et al.: Convergence of mutation and epigenetic alterations identifies common genes in cancer that predict for poor prognosis. PLoS Med 2008, 5:e I I4.

30. Sjoblom T, Jones S, Wood LD, Parsons DW, Lin J, Barber TD, Mandelker D, Leary RJ, Ptak J, Silliman N, et al.: The consensus coding sequences of human breast and colorectal cancers. Science 2006, 3 | 4:268-274.

31. Azzalin CM, Lingner ]: The double life of UPFI in RNA and DNA stability pathways. Cell Cycle 2006, 5: I 496- I498.

32. Azzalin CM, Lingner J: The human RNA surveillance factor UPF I is required for $\mathbf{S}$ phase progression and genome stability. Curr Biol 2006, 16:433-439.

33. Wilkinson MF: A new function for nonsense-mediated mRNAdecay factors. Trends Genet 2005, $21:$ : 43-| 48.

34. Keeling KM, Lanier J, Du M, Salas-Marco J, Gao L, Kaenjak-Angeletti A, Bedwell DM: Leaky termination at premature stop codons antagonizes nonsense-mediated mRNA decay in S. cerevisiae. RNA 2004, 10:691-703.

35. Karam R, Carvalho J, Bruno I, Graziadio C, Senz J, Huntsman D, Carneiro F, Seruca R, Wilkinson MF, Oliveira C: The NMD mRNA surveillance pathway downregulates aberrant E-cadherin transcripts in gastric cancer cells and in CDHI mutation carriers. Oncogene 2008, 27:4255-4260.

36. Song J, Giang A, Lu Y, Pang S, Chiu R: Multiple shRNA expressing vector enhances efficiency of gene silencing. BMB Rep 2008, 4I:358-362.

37. Wheeler DA, Srinivasan M, Egholm M, Shen Y, Chen L, McGuire A, He W, Chen YJ, Makhijani V, Roth GT, et al.: The complete genome of an individual by massively parallel DNA sequencing. Nature 2008, 452:872-876.

\section{Pre-publication history}

The pre-publication history for this paper can be accessed here:

http://www.biomedcentral.com/1755-8794/2/39/prepub
Publish with Bio Med Central and every scientist can read your work free of charge

"BioMed Central will be the most significant development for disseminating the results of biomedical research in our lifetime. "

Sir Paul Nurse, Cancer Research UK

Your research papers will be:

- available free of charge to the entire biomedical community

- peer reviewed and published immediately upon acceptance

- cited in PubMed and archived on PubMed Central

- yours - you keep the copyright

Submit your manuscript here:

http://www.biomedcentral.com/info/publishing_adv.asp
BioMedcentral 